\title{
Thermal Damage of Carbon Fiber Reinforced Plastic by IR Fiber Laser Irradiation
}

\author{
Hiroyuki Niino*1, Yoshihisa Harada ${ }^{* 1}$, and Akira Fujisaki ${ }^{* 2}$ \\ ${ }^{* 1}$ National Institute of Advanced Industrial Science and Technology (AIST), Tsukuba, Japan \\ E-mail: niino.hiro@aist.go.jp \\ ${ }^{* 2}$ Furukawa Electric Co., Ltd., Chiba, Japan
}

\begin{abstract}
We report damage in trenches produced by laser irradiation of a carbon fiber reinforced plastic (CFRP) plate. Laser cutting of CFRP was performed by multi-pass irradiation with a continuouswave fiber IR laser (multi-mode laser, average power: $3.3 \mathrm{~kW}$ ). The damaged sidewall of the trench in the samples was analyzed by microscopic X-ray computed tomography. Low-speed laser scanning with a galvanometer scanner significantly damaged the sidewall surface and created a wide heat-affected zone. As the thickness of the damaged area was correlated with the scanning speed of the laser beam, the damaged region length was analyzed using the heat penetration depth equation. DOI: 10.2961/jlmn.2017.03.0011
\end{abstract}

Keywords: laser micromachining, CW IR fiber laser, CFRP composite, heat-affected zone (HAZ), microscopic X-ray computed tomography

\section{Introduction}

Carbon fiber reinforced plastics (CFRPs) are composite materials consisting of resin matrices and carbon fibers. Laser-induced cutting of CFRPs with a kilowatt (kW)-class high-power fiber laser enables high-speed material processing with an acceptable quality [1-3]. This laser cutting process yields high-precision cuts with a narrow trench [4, 5]. Considerable damage appears on the surface of the trench sidewall after irradiation with a tightly focused beam of a kW-class laser, probably due to the high thermal conductivity of carbon fiber, which is higher than that of the CFRP resin matrix [6-8]. This damage adversely affects the mechanical tensile strength of CFRPs [9, 10]. Previous studies reduced damage by laser cutting CFRP with a fast beam galvanometer scanner using a multi-pass method to avoid heat accumulation [1-3, 11].

In this paper, we report laser-induced damage during laser cutting of CFRPs using a continuous-wave (CW) $\mathrm{kW}$ class fiber laser $(\lambda=1,084 \mathrm{~nm})$. The internal trench microstructure produced by laser irradiation at various scanning speeds was characterized by X-ray computed tomography (X-CT) to identify thermally damaged areas. A nondestructive method like X-CT provides fascinating insight into the spatial variation of composite substrates that display micrometer-size porosity.

\section{Experimental Method}

In the multi-pass method, the output of a near-IR CW laser (Furukawa Electric, Yb-doped fiber laser, $\lambda=1,084$ $\mathrm{nm}$, fiber core diameter $50 \mu \mathrm{m}, 3.3 \mathrm{~kW}$ average power) [2] was used to scan the sample surface in a series of parallel lines using a galvanometer scanner in ambient air without assist gas (scanning speed: $3.6-0.05 \mathrm{~m} \mathrm{~s}^{-1}$, linear scan length: $5 \mathrm{~cm}$ ) $[1-3,11]$. The beam was normally incident on the sample surface and was focused using an f-theta lens (Showa Optronics Co., Ltd., FT300/5-1080F, nontelecentric lens, $\mathrm{f}=306 \mathrm{~mm}$, laser beam diameter: ca. 200 $\mu \mathrm{m})$. The time interval (breaking time) between the scan passes was set to $5 \mathrm{~s}$ to prevent heat accumulation on the sample.

CFRP plates $3 \mathrm{~mm}$ thick were used for the laser cutting in this study. The plates were a commercially available prepreg laminate consisting of thermoset epoxy resin with PAN-based carbon fibers. The lamina consisted of unidirectional fibers stacked in alternating parallel and perpendicular layers (manufacturer: MITSUBISHI RAYON CO., LTD., cross-ply $0 / 90^{\circ}, 12$ layers, $\mathrm{Cf}=70 \%$, sample size:

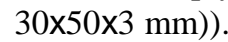

The internal damage to the laser-cut samples was observed with a microscopic X-CT system (Yamato Science Co., TDM1000H-S $\mu / T D M 1600 H-I I$, X-ray filament: LaB 6 , $\mathrm{X}$-ray spot diameter: $0.8 \mu \mathrm{m})$. The dark areas around the trench in the cross-sectional X-CT images was recognized as laser-induced damage area. 


\section{Results and Discussion}

\subsection{X-CT images of CFRP material by laser cutting at various scanning speeds}

Figure 1 shows cross-sectional X-CT images of the trench structure on a CFRP sample obtained after CW fiber laser cutting with an average power of $3.3 \mathrm{~kW}$ using the multi-pass method. The number of passes to completely cut the 3-mm-thick CFRP plates are listed in Table 1 for each scanning speed. The laser irradiation formed a deep trench structure with a high aspect ratio. The kerf at the trench surface was $300 \mu \mathrm{m}$ wide, and the internal trench width was about $200 \mu \mathrm{m}$ wide. The kerf of the trenches was tapered in Fig. 1. This tapered structure would be attributed to the intensity attenuation of the incident laser beam into 3-mm thick-sample.

The dark areas in Fig. 1 are attributed to epoxy resin degradation and evaporation during the laser irradiation. The gray area of the samples in Fig.1 was resin region. Thermogravimetric analysis has shown that the epoxy resin of CFRP thermally decomposes above $300^{\circ} \mathrm{C}$ [12], suggesting that the damaged area was transiently above $300^{\circ} \mathrm{C}$ during the laser irradiation.
As the CFRP sample consists of 12 cross-ply laminates with $0 / 90^{\circ}$ orientations, the damaged area expanded inhomogenously from the sidewall surface into the CFRP bulk. At the fiber layer perpendicular to the laser-cutting direction at scanning speeds of $3.6-0.2 \mathrm{~m} \mathrm{~s}^{-1}$, a large damaged area was observed because the carbon fiber provided the dominant heat conduction path. The top-view crosssectional images in Fig. 2 clearly show epoxy resin degradation without carbon fiber damage.

Table 1 Number of passes required to completely cut through CFRP plates $3 \mathrm{~mm}$ thick at various laser scanning speeds.

\begin{tabular}{cc}
\hline $\begin{array}{c}\text { Scanning speed, } v \\
\text { Number of passes for complete } \\
\text { cutting of CFRP }\end{array}$ \\
\hline $3.6 \mathrm{~ms}^{-1}$ & 60 \\
$0.5 \mathrm{~ms}^{-1}$ & 6 \\
$0.2 \mathrm{~m} \mathrm{~s}^{-1}$ & 5 \\
$0.1 \mathrm{~m} \mathrm{~s}^{-1}$ & 3 \\
$0.05 \mathrm{~ms}^{-1}$ & 2 \\
\hline
\end{tabular}

(a)

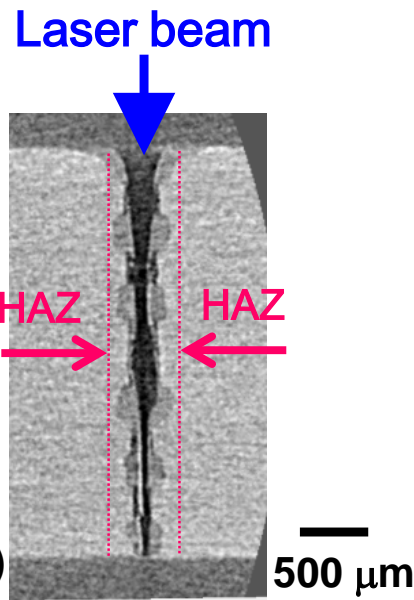

(b)

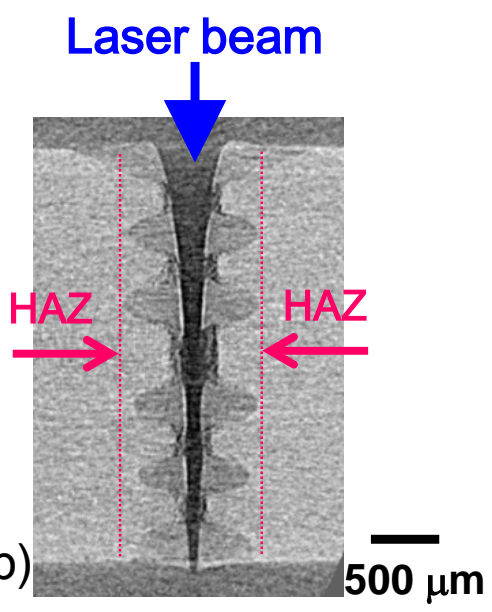

(c)
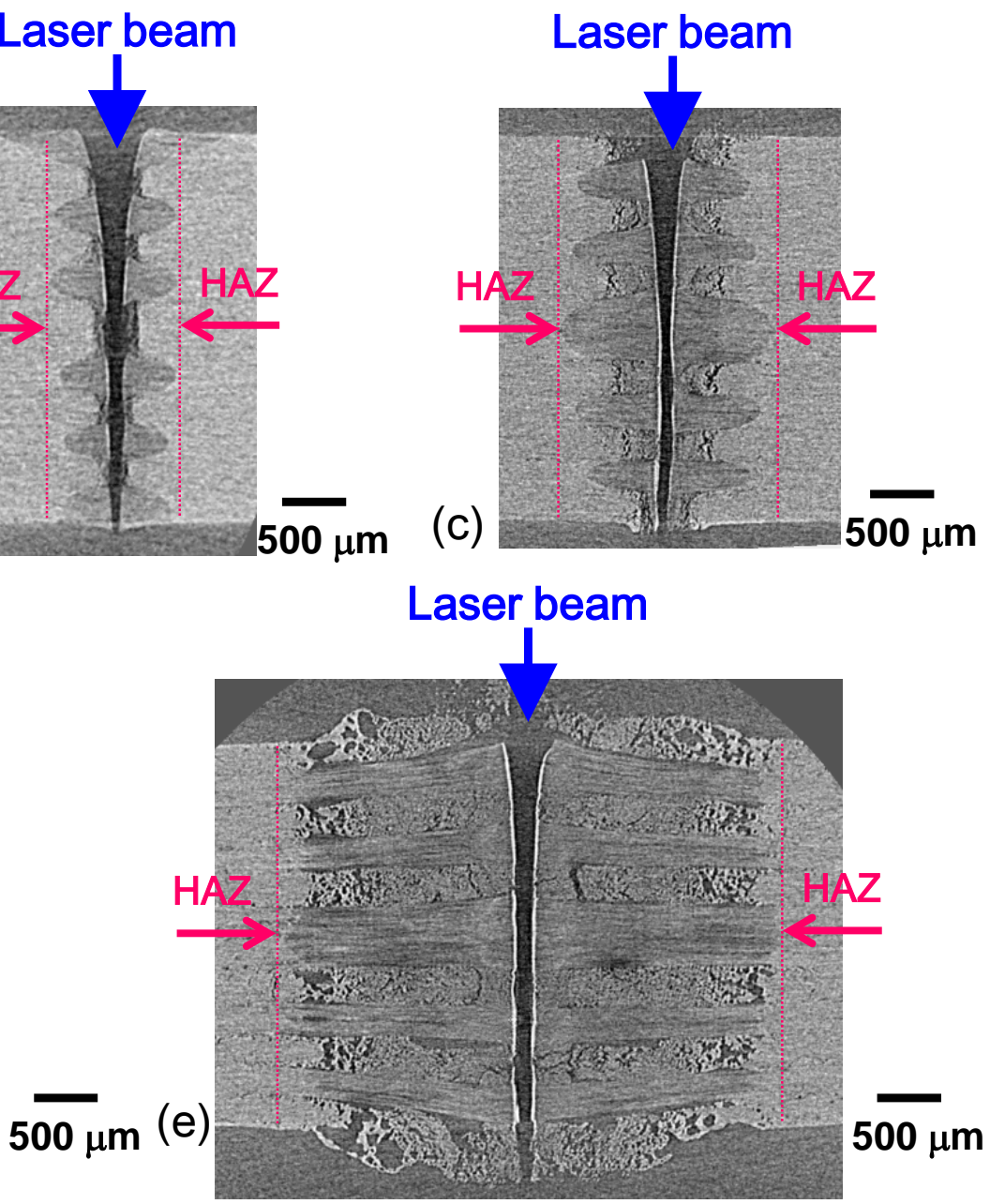

Fig. 1 Side-view cross-sectional X-CT images of 3-mm-thick CFRP plates cut by CW 3.3-kW fiber laser irradiation using the multi-pass method. The laser scanning speed was (a) $3.6 \mathrm{~m} \mathrm{~s}^{-1}$, (b) $0.5 \mathrm{~m} \mathrm{~s}^{-1}$, (c) $0.2 \mathrm{~m} \mathrm{~s}^{-1}$, (d) $0.1 \mathrm{~m} \mathrm{~s}^{-1}$, and (e) $0.05 \mathrm{~m} \mathrm{~s}^{-1}$. Thermally damaged areas are labeled "HAZ" (heat-affected zone). The laser scanning speed of $3.6 \mathrm{~m} \mathrm{~s}^{-1}$ was maximum for the laser irradiation system. 

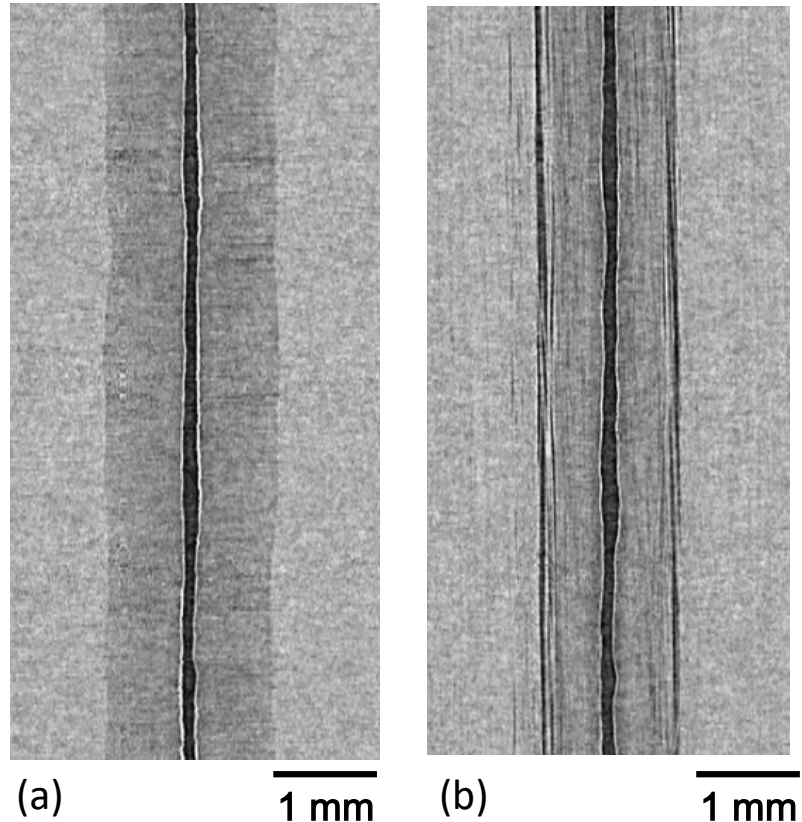

(b)

$1 \mathrm{~mm}$

Fig. 2 Top-view cross-sectional X-CT images of the 3-mm-thick CFRP plate cut by CW $3.3-\mathrm{kW}$ fiber laser irradiation using the multi-pass method (3 passes). The laser scanning speed was 0.1 $\mathrm{m} \mathrm{s}^{-1}$. The section depths are (a) fifth layer from the surface and (b) sixth layer from the surface.

\subsection{Relationship between thermal damage and laser scanning speed}

As shown in Fig. 1, the trench sidewall damage strongly depended on the laser scanning speed, which was varied between 3.6 and $0.05 \mathrm{~m} \mathrm{~s}^{-1}$. Table 2 indicates the maximum thickness of the thermally damaged area produced by laser irradiation in the CFRP plates at these laser scanning speeds. The minimum thermal damage was obtained using a scanning speed of $3.6 \mathrm{~m} \mathrm{~s}^{-1}$.

The laser irradiation time $\tau$ on the sample surface was calculated as follows:

$$
\tau=\varphi / v
$$

Table 2 Maximum thickness of thermally damaged area in CFRP plates produced by laser irradiation at various laser scanning speeds.

\begin{tabular}{ccc}
\hline $\begin{array}{c}\text { Scanning } \\
\text { speed, } v\end{array}$ & $\begin{array}{c}\text { Laser irradiation } \\
\text { time, } \tau\end{array}$ & $\begin{array}{c}\text { Maximum thickness } \\
\text { of thermally dam- } \\
\text { aged area, } L\end{array}$ \\
\hline $3.6 \mathrm{~m} \mathrm{~s}^{-1}$ & $56 \mu \mathrm{s}$ & $180 \mu \mathrm{m}$ \\
$0.5 \mathrm{~m} \mathrm{~s}^{-1}$ & $400 \mu \mathrm{s}$ & $430 \mu \mathrm{m}$ \\
$0.2 \mathrm{~m} \mathrm{~s}^{-1}$ & $1000 \mu \mathrm{s}$ & $770 \mu \mathrm{m}$ \\
$0.1 \mathrm{~m} \mathrm{~s}^{-1}$ & $2,000 \mu \mathrm{s}$ & $1,100 \mu \mathrm{m}$ \\
$0.05 \mathrm{~m} \mathrm{~s}^{-1}$ & $4,000 \mu \mathrm{s}$ & $1,900 \mu \mathrm{m}$ \\
\hline
\end{tabular}

where $\varphi$ is the laser beam diameter (corresponding to the internal trench width of $200 \mu \mathrm{m}$ ) and $v$ is the laser scanning speed. In this experiment, the laser irradiation time $\tau$ was varied widely, from $56 \mu$ s to 4 ms. The maximum thickness of the thermally damaged area $L$ in a CFRP plate is plotted as function of laser irradiation time $\tau$ in Fig. 3. A linear relation between $L$ and the square root of $\tau$ was obtained. The heat penetration depth was defined from the parameters $L$ and $\tau$ and the thermal diffusivity constant $D$ [5]:

$$
L=2 \sqrt{D t}
$$

On the basis of curve fitting using equation (2) for the data in Fig. 3, $D$ was estimated to be about $1.98 \mathrm{~cm}^{2} \mathrm{~s}^{-1}$. Red line in both plots in Fig. 3 are fits using equation (2). This value was almost in agreement with the experimentally measured value for in-plane, uni-directional thermal diffusivity ( $\left.D=2.18 \mathrm{~cm}^{2} \mathrm{~s}^{-1}\right)$ for a CFRP plate [13], suggesting that the damaged area propagated into the bulk CFRP through carbon fibers by a heat conduction during photo-induced thermal process.

Although the damage area in the trench at the laser irradiation of the slow scanning speed (Figs. 1 (d) and (e)) was about the same parallel and perpendicular, the area the fast scanning (Fig. 1(a) and (b)) was much larger parallel then at slow scanning. This would be attributed to a slow heat conduction of resin region $\left(\mathrm{D}=0.023 \mathrm{~cm}^{2} \mathrm{~s}^{-1}\right)$ [13].

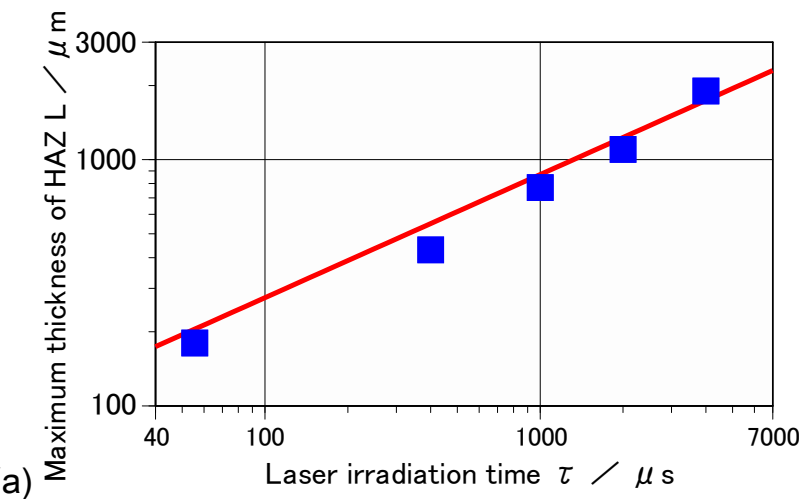

(b) $\stackrel{\pi}{\Sigma}^{\pi}$

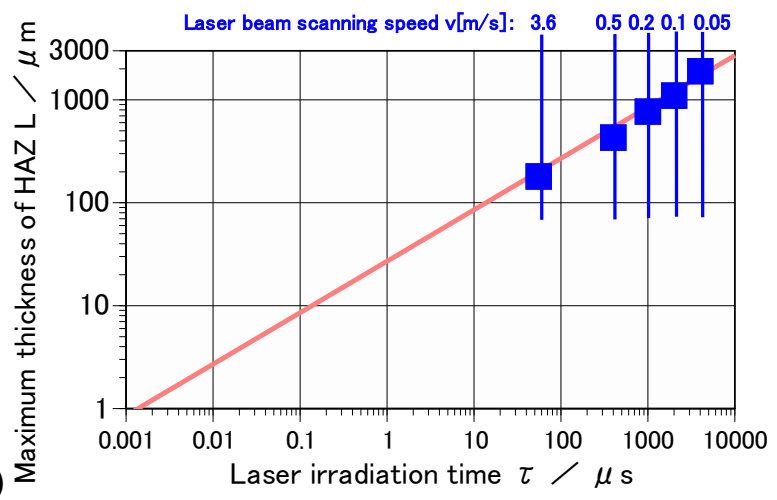

Fig. 3 Maximum thickness $L$ of thermally damaged region plotted as function of laser irradiation time $\tau$. Plots are for (a) microsecond region and (b) nanosecond to microsecond region. Red line in both plots are fits using Eq. (2). 
When Fig. 3(a) was extended to the nanosecond regime, $L$ was reduced to about $10 \mu \mathrm{m}$ for an irradiation time of 100 ns [Fig. 3(b)]. If a scanning system 500 times faster with a high-peak-laser-power or a $\mathrm{kW}$-class nanosecond pulsed laser was employed, the laser-cut trench would exhibit a clean top and excellent sidewall quality, and the thermally damaged region would extend only tens of micrometers from the trench.

\section{Summary}

We have analyzed thermal damage to CFRP in ambient air following multi-pass cutting with a CW near-IR laser. By exploring the damage using the heat penetration depth equation, a systematic analysis of laser beam scanning speed resulted in a good correlation between the laser irradiation time and the extent of damage near the sidewall.

\section{Acknowledgments}

This work was supported in part by the national project "Advanced Laser and Processing Technology for Nextgeneration Materials Project” (High-power Pulsed Fiber Laser and Processing Technology Project), launched in FY2010 for a 5-year period in the Industrial Technology Center of NEDO.

\section{References}

[1] H. Niino, Y. Harada, and A. Fujisaki: J. Laser Micro/Nanoengin., 11, (2016) 372.

[2] H. Niino, Y. Harada, K. Anzai, M. Matsushita, K. Furukawa, M. Nishino, A. Fujisaki, and T. Miyato: J. Laser Micro/Nanoengin., 11, (2016) 104.

[3] H. Niino, Y. Harada, K. Anzai, M. Aoyama, M. Matsushita, K. Furukawa, M. Nishino, A.Fujisaki, T. Miyato, an d T. Kayahara: Proc. of SPIE, 9353, (2015) p.935303.

[4] K. Sugioka, M. Meunier, and A. Piqué, (Eds.): "Laser Precision Microfabrication, Springer Series in Materials Science, Vol. 135”, (Springer-Verlag, Berlin \& Heidelberg, 2010).

[5] D. Bauerle: "Laser Processing and Chemistry (4th Ed.)”, (Springer-Verlag, Berlin \& Heidelberg, 2011) p. 279.

[6] D. Herzog, P. Jaeschke, O. Meier, H. Haferkamp: Int. J. Mach. Tools Manu., 48 (2008) 1464.

[7] R. Weber, T. Graf, P. Berger, V. Onuseit, M. Wiedenmann, C. Freitag, and A. Feuer: Opt. Express, 22 (2014) 11312.

[8] D. Herzog, M. Schmidt-Lehr, M. Canisius, M. Oberlander, Jan-Philipp Tasche, and and C. Emmelmann: J. Laser Appl., 27 (2015) S28001.

[9] M. Nishino, Y. Harada, T. Suzuki, and H. Niino: Proc. of SPIE, 8243, (2012) 82431C.

[10] Y. Harada, K. Kawai, T. Suzuki, and T. Teramoto: Mater. Sci. Forum, 706-709, (2012) 649.

[11] H. Niino, Y. Kawaguchi, T. Sato, A. Narazaki, R. Kurosaki, M. Muramatsu, Y. Harada, K. Wakabayashi, T. Nagashima, Z. Kase, M. Matsushita, K. Furukawa, and M. Nishino: J. Laser Micro/Nanoengin., 11, (2016) 180.

[12] T.Ohkubo, M.Tsukamoto, and Y.Sato: Appl. Phys. A, 122, (2016) 196.

[13] R.Fujita and H.Nagano: Compos. Sci. Technol., 140, (2017) 116.

(Received: June 14, 2017, Accepted: October 22, 2017) 